\title{
En busca de la cocina perdida. Los singulares instantes del quehacer de cocinar ${ }^{*}$
}

\begin{abstract}
Resumen
Este artículo invita a reconocer una cocina de enseres y quehaceres, una atención del diseño a la olvidada vida cotidiana para saber de lo que al cocinar y en la cocina se hace en realidad. Una intención del diseño para combatir el olvido de su quehacer, de su vivencia o simplemente lo que cocinar hace para el ser humano. Es una búsqueda de la cocina vivida que recabó en el pasado de las cocinas del mundo y que fue acercando su atención en los sucesos de las cocinas propias de ciudad en la actualidad. Esto fue una mirada de la cocina lejana de su apariencia, del diseño y tecnología como mera utilidad, para más bien reparar en lo que de importancias Ilena la cotidianidad. Por tanto en busca de la cocina perdida, rastrea cómo los objetos hacen parte de nuestra vida, artefactos que salvados de su insignificancia manifiestan un nuevo discurso entre diseño y vida cotidiana, el de una cocina auténtica que está en el cocinar.
\end{abstract}

\author{
Sandra Marcela Bustacara \\ Panzza \\ Magíster en Diseño y Creación \\ Interactiva \\ Docente Universidad Jorge Tadeo \\ Lozano \\ Bogotá, Colombia \\ Correo electrónico: sandram. \\ bustacarap@utadeo.edu.co \\ (1) orcid.org/0000-0001-7289-6190 \\ Google Scholar
}

Recibido: Octubre 25 de 2017

Aprobado: Septiembre 24 de 2018

Palabras clave:

Cocina, artefactos, diseño, tecnología tradicional, vida diaria.

\footnotetext{
* Este artículo es el resultado de la investigación: "La cocina. Diseño y vida cotidiana. Una revelación del envés de sus objetos". Realizada en la Maestría de Diseño y Creación Interactiva de la Universidad de Caldas.
}

Revista KEPES Año 16 No. 19 enero-junio 2019, págs. 123-149 ISSN: 1794-7111(Impreso) ISSN: 2462-8115 (En línea) DOI: 10.17151/kepes.2019.16.19.6 


\section{In Search of the Lost Kitchen. The singular moments of cooking}

\begin{abstract}
This article invites to recognizing a kitchen of utensils and chores, an attention of design to the forgotten daily life to know what is really done when cooking and in the kitchen. An intention of design to fight the oblivion of its task, of its experience or simply what cooking gives to human beings. It is a search for the lived kitchen that managed to get information from the past of the kitchens of the world and that was approaching its attention in the events of the kitchens proper of a city at present. This was a view of the kitchen far from its appearance, of design and technology as mere utility to rather repair what fills of importance everyday life. Therefore, in search of the lost kitchen traces how objects are part of our life, artifacts that saved from their insignificance, manifest a new discourse between design and everyday life, that of an authentic kitchen that is in cooking.
\end{abstract}

Key words:

Kitchen, artifacts, design, traditional technology, daily life. 


\section{Introducción}

Este artículo es el resultado del proceso de investigación del posgrado en Diseño y Creación Interactiva de la Universidad de Caldas en el que se estudió la cocina desde los significados de sus artefactos; una cuidadosa atención en el diseño y la cotidianidad que alberga este lugar. Este estudio señala el propósito de revelar una cocina despojada de apariencia, reconocida en el envés de sus objetos; en esos significados que dan cuenta del quehacer, de la vivencia, de la resonancia que tiene lo cotidiano. $Y$ es porque la cocina es un lugar altamente atendido por la tecnología, el diseño y la publicidad. Una atmosfera de lo físico, de materiales, de renovación, de orden, color y de exigencia. De slogans sobre mejores tiempos que contemplan la rapidez, la practicidad y la liberación de todo lo perpetuo. Es decir una cocina así establecida como una alegoría, que se expande entre la contemporaneidad como el aligerado esmero que se debe a este lugar. $Y$ en contraste un menor interés atendido desde el diseño a su vivencia, a hacerla real y no confundir sus procesos en extremada apariencia; una ratificación del diseño como imposibilidad para sacar aquel lugar del menosprecio al sobrellevar tan ardua labor, aquella de cocinar.

Es por esto que la indagación de aquello que no se ve o que está en suspensión, que no suena y que poco se siente, es en realidad lo que es la cocina; pues vivenciarla está en juntar toda su dotación para cruzar lo cierto de los alimentos, el agua, el fuego con el ser humano; que tocando aquí y allá logra convertir a todo esto en actuaciones, en las idas y vueltas de un quehacer, del aprecio por lo que al cocinar se desprende del ser humano. Por ello en busca de la cocina perdida rastrea lo que perdido se ha vuelto para la cocina con la intención de combatir el olvido de su quehacer, de su vivencia o simplemente lo que cocinar hace para el ser humano. Por lo tanto artefacto, significados y cotidianidad son los aspectos que resalta este estudio porque al diseño no solo le anima a transformar sin detención el mundo, sino también le inquieta saber 
que esas configuraciones cuentan mucho del ser humano. De usos, desusos, apegos o meramente de artefactos que más que una apariencia y un material hablan de lo que en realidad somos.

Por lo anterior, la cuestión que alimenta esta investigación está en el cómo reavivar la adhesión a la realidad de significación que tiene cocinar; desvanecida y desestimada por la sugestiva y aseverada apariencia de la cocina resuelta por el diseño. Y la tesis que defiende es la de reivindicar lo cotidiano. Una oportunidad para acoger los nuevos rumbos del diseño y provocar nuevos discursos sobre artefactos tal como lo manifiesta desde la experiencia Richard Buchanan (2001) o como también lo reclama Krippendorff (2006) sobre los artefactos al estar pensados para generar algo nuevo en las personas, o incluso la crítica sobre el sentido común carente en el diseñador que reprocha Donald Norman (2010). Y todo esto para colocarlo adyacente a teorías sobre "el olvido de la cotidianidad" que resalta Adolfo Grisales (2015). O sobre "la vida de las cosas" que presenta Remo Bodei (2013). Y sobre lo que Henry Lefebvre (1987) dejo en suspensión en su escrito "Lo cotidiano y la cotidianidad". Por tanto, recobrar voces y actuaciones de un quehacer como cocinar es reivindicar entre lo simple y rutinario también lo durable e indispensable.

Los estudios sobre la cocina muestran un amplio despliegue en temas gastronómicos, en la historia y evolución de sus artefactos, sobre aquellos tiempos donde la cocina dejó de ser un lugar oscuro, sucio y abandonado para transformarse en bonito, distinguido y deseado en sofisticación. Unas investigaciones sobre el movimiento moderno y su influencia en la sociedad cambiante que recorren épocas y las entrelaza con alimentos, costumbres y artilugios como lo hace Bee Wilson (2013). También enfocados solo a la trasformación de sus artefactos y al paso de la mecanización de la cocina como la hace cuidadosamente Sigfried Giedion (1978). A hacerle frente a la estética de los desperdicios como Ellen Lupton y J. Abbott Miller (1995) lo 
muestran en los desarrollos de los objetos que llenaron las cocinas después de los años 30. Sobre la casa y su sentido interior y donde las mujeres fueron "heroínas del espacio" como lo expresa Carmen Espegel (2007) al intentar estas mujeres arquitectas darle un nuevo aire a las cocinas y a otros espacios de la casa ligados al nuevo espíritu. O también sobre la cocina de tiempos más cercanos y que debe ser repensada en una realidad donde se cocina de vez en cuando, donde se puede compartir la cocina con otros o donde puede ser también una entretención según Otl Aicher (2004). O como las maneras de "hacer comer" tomadas en relevancia por Luce Giard (1999) como aquellas maneras de estar presente en el mundo.

Y también mencionar a aquellos que sobre cocina y cotidianidad lo elevan a un lugar más auténtico como la literatura de Laura Esquivel (2015) o las narraciones sobre costumbres que de la cocina tiene Manuel Mejía Vallejo (2011). Y sobre las investigaciones de cultura, costumbres de alimentación, comida y literatura que recoge la Biblioteca básica de Cocinas Tradicionales de Colombia. O sobre lo que la alimentación y sus procesos cuentan de la estructura de una cultura como lo manifiesta Claude Lévi-Strauss (1970). O sobre el estudio del gusto un placer estético que explica Carolyn Korsmeyer (2002) y que eleva al igual que Francesca Rigotti (2001) a la cocina y a los alimentos a un lugar de sensaciones y quehaceres, así como de metáforas con la explicación de la importancia de la vida a través de lo que parece más trivial como son los quehaceres al cocinar y al degustar.

Es con lo anterior una profunda motivación a reunir sobre los logros de estos investigadores una cocina de artefactos y de diseño, pero también una cocina de vivencias. Es sobre todo una cocina donde se logra hablar de lo que allí sucede, de lo que significa y devela al ser humano. Por lo tanto no es el diseño distinguiendo su apariencia, es el diseño comprendiendo su quehacer a través de aquellos objetos que pasan una y otra vez por las manos; que se desgastan, 
se vuelven imprescindibles, aunque abollados se encuentren o modernos se manifiesten; solo junto a los otros y con el quehacer cuentan de lo que allí, en instantes, hace a la cocina un lugar no solo de recetas o electrodomésticos sino un lugar de quehacer, del ser humano hacedor, un lugar así de encuentros.

Por ello recuperar del hacer en la cocina voces y actuaciones en los que el ser humano participa y se hace vivo porque transforma con su propias manos el mundo, está en la construcción de un nuevo discurso sobre la domesticidad, donde la reivindicación de lo cotidiano lleve a su quehacer a un lugar de importancias y de alejar aquel equivocado carácter negativo con el que se ha acostumbrado al saber de cocinar; es, además, poner sobre la mesa y de insistir que la cocina es más que toda la utilidad que el diseño y la tecnología manifiesta.

En este sentido la revisión de documentos teóricos sobre vida cotidiana, artefactos y modernidad como "La cosa" de Martin Heidegger (1953) y La intuición del instante de Gastón Bachelard (1986), son la primera etapa en la que esta investigación consolidó su discurso y con el mismo emprendió un segundo momento para el encuentro de los instantes de la cocina; aquellos momentos perdidos que comenzaron a aparecer en la interpretación de observar lo observado en otras investigaciones, en la fotografía, en el arte digital, en el cine y en reales cocinas nuestras. Esto es un conjunto de estrategias desde la observación para descomponer las imágenes entre significado y artefactos presentes, y recomponer con esto una narrativa sobre la cocina por medio de la interpretación de aquellos instantes reveladores de esa intimidad de múltiples cocinas campesinas y de ciudad.

Así que este documento se presentará en tres estados: el primero mostrará lo referido a lo olvidado que tiene el quehacer, en donde se mostrará esas separaciones entre diseño y vida cotidiana; el segundo apartado se refiere a 
los aspectos escondidos que tiene cocinar y que se argumentarán desde el acontecimiento. Y por último se expondrá la cocina vivida una conjugación entre artefactos, alimentos y ser humano, aspectos que en realidad surgen al cocinar; una reconciliación entre diseño y las maneras de hacer que hablan de aquel ser humano que intenta esta ardua labor. Es entonces el rumbo para hallar lo que de la cocina perdida se encuentra y descubrirlo en su misma vivencia.

\section{Metodología}

En relación a la metodología empleada, esta investigación construyó una mirada de la cocina a través de las posturas teóricas de Heidegger (1953), (1964), Bachelard (1986) y de Aicher (2004); una base conceptual que determinó el acierto de detenerse a observar de la cocina los instantes de su quehacer. Esto fue consignar la imagen de la cocina detenida en fragmentos relevantes, momentos que han quedado como registro de lo que ha sido la cocina. Fue una observación de lo observado, una lectura de vivencias, de acontecimientos que han surgido entre la cotidianidad de cocinar. Que retomó registros fotográficos de otras investigaciones a nivel del desarrollo de la cocina en el mundo, de múltiples cocinas regionales en originales tomas de instantes de quehacer, en las imágenes de la cocina en las artes y las múltiples escenas en el cine.

Aquí es preciso mencionar que la cocina es un lugar de escasa y fragmentaria documentación y registro visual; en la consulta de revistas, libros, archivos existen amplias descripciones y narraciones con una disminuida muestra visual que presente lo expuesto. En este sentido para la observación y descripción de la cotidianidad, que permitió rescatar lo oculto de las cocinas a través de lo escrito y hacerlo evidente a través de la imagen, un entretejido entre lo visual y lo narrativo fue necesario descomponer las imágenes para lograr contrastarlas 
desde los extremos teóricos que muestra lo cotidiano; la monotonía y el acontecimiento, dos ámbitos que se tocan cuando el quehacer es manifestado en instantes (Figura 1). Y esto es lo que cada imagen guarda, instantes que se analizaron desde lo físico y desde lo significativo. Una observación con detección de aquellos instantes congelados para recomponer al describir y mostrar la cocina como un lugar para vivir.

Además fue necesario el redibujo de algunas imágenes porque eran limitadas, fraccionadas, dispersas y muy poco detalladas; se debió juntar segmentos de imágenes de cocinas con sus planos y volver a dibujarlas para comprender hasta donde el diseñador de los años veinte llegó a configurar los modos de vida. De igual manera este redibujar fue utilizado en las cocinas de hoy de la ciudad, a partir de las fotografías tomadas por sus mismos dueños para la construcción de los mapas mentales. Este instrumento es tomado del artista holandés Jan Rothuizen ${ }^{1}$, quien logra entrar en la intimidad doméstica y la cotidianidad de la ciudad al redibujar el lugar visitado y plasmar sobre el mismo algunos significativos textos. Esto es un dibujo enriquecido y vuelto mapa mental, un diálogo sobre la cotidianidad a través del texto y del dibujo. Esta investigación tomo dicho método para entrar sin molestar en la intimidad de las cocinas de muchas personas, sin realmente ser invitado, sin intimidar. El redibujo y textos fueron elaborados por los dueños de las cocinas y permitieron saber de sus objetos, de sus hábitos y pensamientos; esto fue saber cómo son nuestras cocinas, en lugar de cómo se han pensado y a la vez la base que facilitó describir las vivencias más significativas en estas cocinas.

'Artista invitado a la Feria del Libro de Bogotá, en 2016, donde dibujó y presentó mapas sobre la cotidianidad de Bogotá y de su país Holanda. Ver trabajo en http://janrothuizen.nl/. 


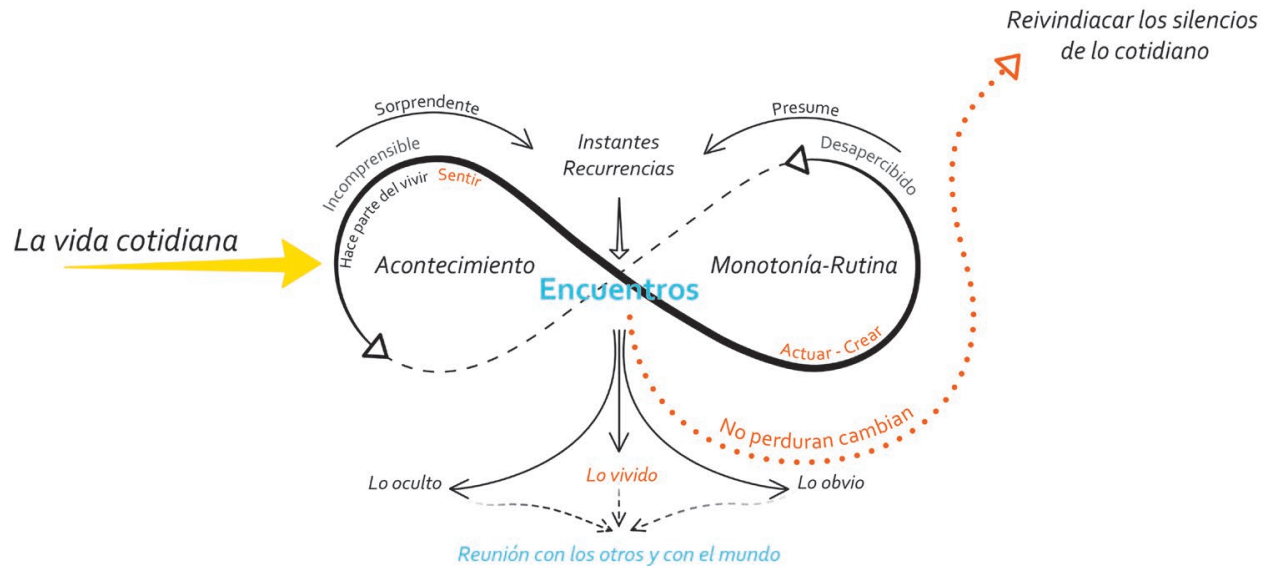

Figura 1. Síntesis conceptual. Cocina, diseño y vida cotidiana. Fuente: elaboración propia por parte de la autora.

\section{Resultados y discusión}

\section{En la cocina: un olvidado quehacer}

Este apartado mostrará la majestuosa transformación que tuvo la cocina; un vuelco a lo irreconocible porque dejo de ser un lugar abandonado y apartado de la casa para introducirse dentro de esta y ocupar un lugar diferenciado, ordenado y determinado. Un esfuerzo que en manos de mujeres, arquitectos e ingenieros fragmentaron funciones y decidieron llevarla a procesos y recorridos; un orden continúo que en suma es la espectacularidad de su apariencia y también el panorama de un quehacer desvanecido, de un ser humano lejano a vivenciar la cocina y más bien atrapado entre esta para siquiera producir o fabricar alimentos. 
La historia de la cocina es la historia de las coincidencias, de los aportes de hombres y mujeres, de los tiempos de escases del servicio domésticos, del impulso por los desarrollos tecnológicos en artilugios y alimentos, de las ciudades en crecimiento, de las enfermedades que se expandían por la falta de higiene; y a todo esto también el de la mujer, que interesada en ampliar fronteras estudió y tomó por su cuenta conocimientos sobre domesticidad y los Ilevó hasta cientificidad. Son estos algunos aspectos en los que la sociedad a mediados del siglo XIX se vio enfrentada. Una confluencia que favoreció para que el ser humano se detuviera a mirar lo que siempre ha estado allí, el lugar donde sale la comida con la que todos los días alimenta, una necesaria revolución que entró a las cocinas del mundo para separar de las ardientes brazas y de las mismas formas de cocción al ser humano y para mostrar que los utensilios de la cocina modificados y ampliados permiten disfrutar a los alimentos de muchas formas y también para entre mejoras, ayudas o facilidades escapar de este interminable quehacer.

Sin duda saber de su origen es mencionar a Catharine Beecher; una mujer americana que esbozó la cocina organizada a través de estantes, muebles que se juntan a las paredes y de los que sobresalen superficies para organizar los procesos. Una cocina con una estufa separada por puertas corredizas, con bomba de agua en el fregadero y con un lugar específico para colocar las vajillas o las cacerolas de preparación. Fue esta mujer, según Corrodi (2006), quien se tomó el esfuerzo de organizar la cocina doméstica como similitud a las cocinas de la época de los barcos a vapor que recorrían el río Misisipi. Una adaptación con un rotundo giro porque las cantidades de alimentos que salen de una familia no son tan grandes como lo es en una cocina que atiende a muchos marineros. Pero si una cocina de procesos, así que Beecher produjo etapas continuas con herramientas al alcance; tanto así que le dio un lugar privilegiado a la harina porque según Beecher, citada por Giedion (1978), "la verdadera ama de casa hace de su pan el soberano en la cocina" (p. 525). Así 
que juntó, ordenó y detalló con la intención de reducir pasos para que la mujer no se desgastara y pudiera cuidar a su familia e incluso dedicarse a realizar deporte, a cuidar su salud. Una atención a la cotidianidad de la mujer que la llevó a escribir documentos como el publicado en 1841: "El tratado sobre economía doméstica para el uso de damas jóvenes en casa y en la escuela"; el cual fue muy difundido y tocaba no solo a la mujer de clases acomodadas, sino también a la mujer que trabajaba y mantenía su hogar: que no habla de decoración sino de cómo preparar un presupuesto, de cómo llevar un hogar, de cómo ser la mujer que administra el centro del hogar. Esto es un lugar distinto para la mujer, un lugar en la sociedad como parte indispensable porque ella sería el motor de la familia.

Un cambio que sacó a la cocina de un descuidado lugar; que incluso para muchas culturas como la romana o la griega no tenía lugar definido y en las ciudades europeas de principios del siglo $X X$ se reflejaba como un lugar que no era nada, sin precisión, pretensión o detalle del que Bee Wilson (2013) refiere:

[...] la cocina no estaba en ningún sitio y en todos a la vez. En ningún sitio, porque los habitantes carecían de todo lo que se necesitaba para cocinar: un fregadero, una superficie de trabajo y un lugar donde almacenar alimentos. En todos, pues no se podía escapar de la pestilencia y el calor del fuego. (p. 319)

Las expansiones de la cocina también fueron tomadas por el interés de hombres como el conde de Rumford, quien se encargó de la perfección del fogón al sacar el humo de la casa y al elaborar unos fogones donde no se desaprovechara la fuente de calor; estos son aportes favorecedores a un lugar tan relegado como la cocina; sin embargo son también una demostración que abre una serie de contradicciones, en especial de lo que en realidad libró las mejoras de este lugar, pues los avances fueron apareciendo poco a poco hasta dejarla bien acondicionada: como recoger el agua en grifo o encender 
la estufa y a controlar el fuego con solo girar un botón, incluso a tener un refrigerador y no esperar que el distribuidor de hielo llegara a suministrar; todo esto, y mucho más, para cuestionar el poco entusiasmo que para la mayoría es cocinar. Y que es necesario reclamar sobre esta abundante experimentación que lleva a pensar de lo que entre trasformación y mejores tiempos se ha disuelto del quehacer de cocinar. En este sentido valdría la pena preguntarse: ¿fue el desarrollo de la cocina la liberación del desaseo, del desorden o más bien el acento a la liberación de la monotonía, del encierro y de las ganas de hacer otra cosa menos que cocinar? $\mathrm{O}$ ¿fue la garantía de que eran mejores y nuevos tiempos, lo que perdió de vista la realidad de lo que se hacía en ese lugar? $\mathrm{O}$ ¿el desgano por este quehacer, está en el extremado orden propuesto por los interesados en búsqueda de una mejor cocina? O, en suma, ¿cocina y cocinar se separaron en su exploración? Son estas inquietudes las que se cruzan con lo que para hoy es una cocina porque teniéndolo todo, incluso hervidores para avisar del punto de ebullición u ollas arroceras que hablan sobre el proceso de cocción, la cocina es una paradoja; un desvanecimiento en actuación y esfuerzo enfrentado a acumulados y estudiados artefactos para dejar en suspensión en aquel desarrollado lugar.

En consecuencia la atención en detalles de mujeres, arquitectos o ingenieros desbordó la inmensa popularidad de aquello que hace la vida más fácil; de aquello que hace estar menos en la cocina. Cabe mencionar aquí que después de Beecher han sido más las mujeres las que han intentado configurar la cocina. Christine Frederick, sucesora del pensamiento de Beecher, involucró las ideas del taylorismo del que se desprendió el concepto de ingeniería doméstica. Y Lillian Gilbreth, quien trató a la cocina como un tema de producción industrial. Ideas que atravesaron continentes y que en Europa permearon a Charlotte Perriand en la cocina de Marsella —una americanización de la cocina en Europa para 1950- o Margarete Schütte-Lihotzky con su famosa cocina de Frankfurt en 1926. Entonces, sin proponérselo, estos pensamientos 
que revolucionaron la cocina también condujeron al abandono del quehacer y no creo que sea por solo coincidencia que aquellas impetuosas mujeres promotoras de un cambio, de una valoración a un oficio, de dignificarlo, se halla trastocado tanto; pues entre más posibilidades que libran al hacer del hombre, también aumenta el olvido por los quehaceres. Por tanto, intereses que transformaron a la cocina de cenicienta a protagonista son el infortunio de saber que tal esfuerzo ha quedado entre pasivos espacios y fríos fogones porque puede más desanimar su arreglo y perfección de lugar que las ganas de aquel caos que se genera al cocinar.

Explican Lupton y Miller (1995) y Giedion (1978) que el centro de la trasformación de la cocina no fue su tecnología es para sorpresa de muchos el desarrollo del mueble y su punto de partida fue la organización. Es por ello que la cocina racionalizada se llenó de gabinetes, todo se ajustó a medida para que nada generara tropiezos en su recorrido, guardó el desorden y promovió que cada vez que se tenga que preparar algo se vea la necesidad de abrir y cerrar una infinidad de veces aquel mobiliario que perfecto y lustrado también se hace intocable porque las huellas de su acción obligan a limpiar y limpiar. Por tanto, diseño y tecnología de la mano han hecho de la cocina un fantasioso lugar para convencer a labradoras familias de mejores tiempos y donde la cocina libraría de amplio esfuerzo, el lugar más automatizado de la casa; un sueño hecho realidad en la promoción sobre "la casa del futuro", expuesta en Tomorrowland California en 19572, donde muchos objetos se ocultan y se abren compuertas con la vajilla ordenada o donde se despliegan del techo varias secciones del refrigerador, una idea que quedó en la mente de todos, el sueño de la cocina americana; que se anhela, se espera, y se hace insuperable porque esta envoltura de las cocinas han hecho al más sencillo interesado pero también en alguien muy exigente. Al respecto, refiere Espinet (1984):

Proyecto desarrollado en 1957 por la empresa norteamericana de biotecnología Monsanto, el MIT y la división de ingeniería de Walt Disney. Ver detalles en https://www.youtube.com/watch?v=G2 IrD-ogW6c. 
ya no se admiten dos fuegos arrinconados en una mugrienta y sórdida cocina mal iluminada. Se reclama fachada a la calle, lavadero independiente, armarios de madera noble y hasta si el espacio lo permite, un comedor dentro de la cocina. (p. 128)

En tal caso mujeres que con detalles cautivaron por lo menos en el aspecto y organización de aquel recóndito lugar, de olores molestos, de sacrificios de animales, de desperdicios, un lugar lejano de la casa, de peligros y de incendios. Un aporte del que no cabe duda, ya que hoy se cocina en aquellas cocinas y se cuenta con solo un clic para encender el fogón. No obstante, una apariencia que quedo enclaustrada en admiración como una cocina que no se debe desordenar porque cocinar desacomoda lo que con perfección aquellos intentaron acomodar. Por ello en la cocina un olvidado quehacer por la aguda simpatía a la renovación material, a la ilusión de bienestar, un sobrepaso en busca de ligereza que acogió su aspecto como una disculpa de mejores tiempos. Una adherencia entre apariencia y volátil facilidad que borró del camino tomar en cuenta el considerable desgano que siempre ha implicado cocinar. Y es algo que, por más ingenioso pensamiento, el diseño no ha podido trasformar: el desapego a este oficio del hogar porque es más el abandono hoy que las ganas de intentar cocinar. Es sin duda el diseño promotor de tan extrañan apatía, un descuido a toda su laboriosidad. Un trato de la cocina diluido entre el impreso protagonismo vanaglorioso del diseño y la disolución de todo carácter para cocinar. Un desprecio al fin de cuentas no solo de apariencia y arrinconado lugar sino, aún más, de todo lo que implica cocinar (Figura 2). 

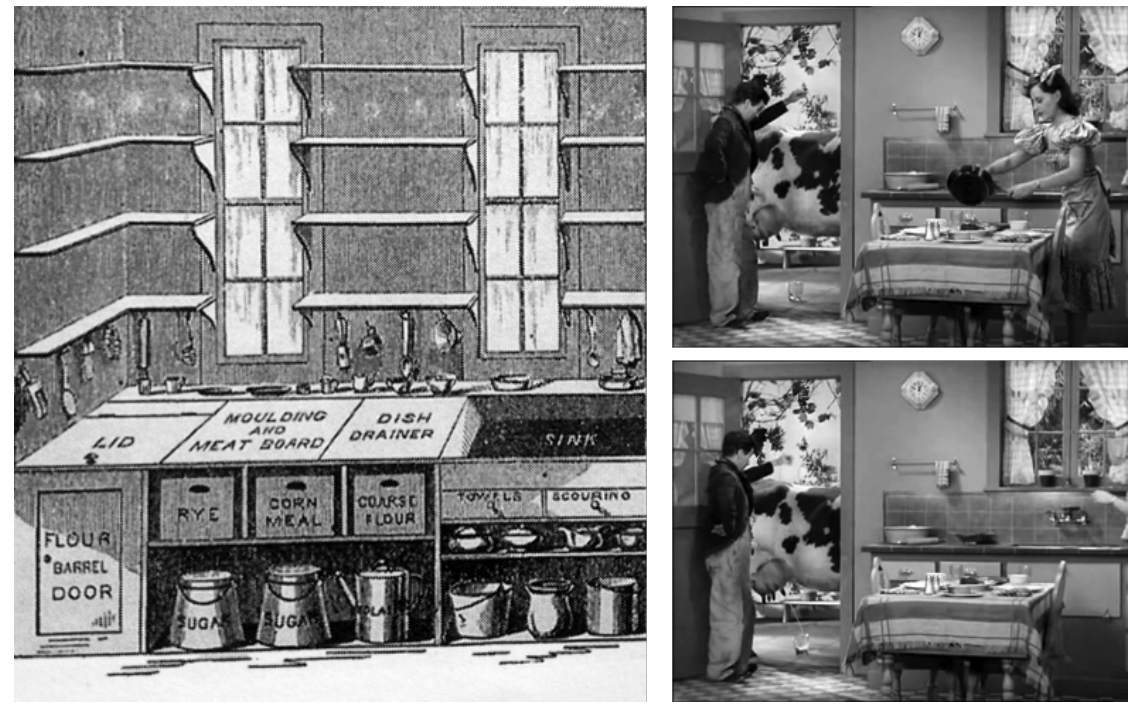

Figura 2. Ordenar, ajustar, detallar y olvidar. De la cocina de Beecher, al ensueño doméstico. Fuente: cocina esbozada por Beecher y película Tiempos modernos de Chaplin.

\section{En la cocina y en el cocinar: escondidos momentos domésticos}

El contenido que se presentará se detiene a mostrar de la configuración de instantes en la cocina, de la relación entre lo que sucede en el presente y en el actuar. Una manera de reconocer lo que es la cocina porque distinguir el tiempo de su quehacer en acontecimientos amplió la convencional mirada de utilidad, de artefacto físico o de proceso. Un intento por cambiar el sentido de duración y monotonía que tiene el quehacer de cocinar hacía más bien unos instantes de sorpresa y transformación que surgen y pasan entre la obviedad que, aunque escondidos, por lo general están en el cocinar. Fue la construcción teórica con la que esta investigación presentó un nuevo discurso sobre la cocina y sobre cocinar. 
Según Wilson (2013) "las cocinas solo cobran vida cuando cocinamos en ellas; la tecnología y los inventos están condicionados por el uso que les damos" (p. 337). Y es así que se activan afinidades entre artefactos y el hombre al cocinar, tornándose conveniente los modos de vivenciar la cocina; pues cada quien elige qué colocar, dónde colocarlo, cómo hacerlo e incluso que preparar. Sin embargo en la cotidianidad de este quehacer la premura, los procesos repetidos al parecer no llevan a una situación original. Ya que en la cocina prima lo incesante, una condición para quedar allí ocupado alrededor de tareas al llevar adelante una preparación. Un hacer, una condición de pensamiento y actuación en la que el ser humano no se detiene a reparar lo que de importancias Ilena la cotidianidad.

En este sentido es oportuno buscar desde la obviedad de la cotidianidad y entre el diseño aspectos que rescatar de la experiencia humana, del hacer, del construir, del participar, de la actividad misma. Según Aicher (2001): "la esencia de las cosas se reduce a lo cotidiano, lo general a lo concreto, lo particular a lo común y corriente, lo hondo a lo aparente y el ser a lo útil, al uso" (p. 292). En efecto, en el uso de artefactos cotidianos se devela el ser humano, se deja ver en su realidad, se conoce y reconoce como ser actuante en el mundo como ser productor, hacedor y partícipe de una forma de vida. De esa que Aicher (2001) reclama que no es la de los domingos solamente, es la de todos los días; una vida cotidiana de esfuerzos, de lo común y corriente donde realmente se vive la vida porque aclara que "en lo común se despliega la cultura como la forma que cada uno de nosotros da a su vida" (p. 300). Y es precisamente como lo dice Anatux Zabalbeascoa (2004): ¿y hay algo más común, corriente, anónimo y cotidiano que cocinar? (p. 9).

Aún más, Heidegger se refiere a situaciones tan sencillas como el cántaro —en el artículo "La cosa" (1953) - para explicar los complejos sucesos significativos que surgen entre hombres y objetos y que revierten a una cercanía, hacia 
el vivir, al actuar. Así que "referirnos ahora a las cosas a nuestro alrededor. Dirigimos nuestra mirada a lo más próximo, a lo asible" (Heidegger, 1964, p. 16). Es ante todo aproximarse a lo real, a las cosas, develar cómo los artefactos son el tránsito que ocasiona la cotidianidad cuando entre los significados del actuar humano los acontecimientos hagan la diferencia en los modos de vivir lo cotidiano.

Razón por la cual, para Heidegger y Bachelard, los acontecimientos comparten lo momentáneo; ello que se da en el ahora. Aunque con posturas un poco distintas coinciden en validar el presente como el lugar en el que el ser humano se encuentra a sí mismo y explica su razón de existir. Y concuerdan en aceptar el pasado, no en lo que se ha hecho como recuento histórico sino el lugar donde hay cosas que requieren ser actualizadas, notadas, esclarecidas, solo porque siguen presentándose y sorprendiendo en la cotidianidad. Para Heidegger (1964): "el mero pasado no agota lo sido. Este está presente todavía, y su forma de ser es una peculiar quietud del acontecer, cuya forma se determina a partir de aquello que acontece" (p. 48); mientras que para Bachelard (1986): "el pasado deja una huella en la materia, por tanto pone un reflejo en el presente y por tanto siempre está materialmente vivo" (p. 55). En este sentido los artefactos involucrados en los quehaceres son traídos a un nuevo comenzar cada día, aunque se sienta habitual y sin novedad entre estos instantes aparecen impregnadas esas cosas que han pasado y permiten que se actúe en el presente; reafirman lo que se hace, expresan como es la realidad y posibilitan mejorar día tras día. Como en las ollas de todos los días, las que han acompañado por años el cocinar muestran como el pasado se actualiza una y otra vez. A pesar de lo abolladas que estén y sean lo más viejo que tenga la cocina entre más cuidadas, abrillantadas, saboreadas, en fin, usadas hayan sido, más estos rastros pasados fundamentales y notorios se manifiestan hoy. Pues en la renovación de su uso se plasma un mayor número de estrategias que hacen mejorar las características del cocinar. 
Por esta razón, leer la cocina desde el acontecimiento la desliga de saber cuántos objetos más se han sumado o que más le hace falta. Es dejar de mirarla como el aditamento de artefactos que el diseñador ha dispuesto para atender lo que en esta se vive junto con lo que se tenga; pues el acontecimiento permite volverla a ver desde lo que allí sucede, en la interioridad de la cotidianidad y en la integridad de su quehacer. Es la respuesta a recorrer la cocina como corresponde dado que la cocina es un lugar de progreso, de perfección como 'cuaternidad', como espacio de encuentro entre humanos y dioses, cielo y tierra, de coincidentes momentos para agasajar. Cocinar es configurarla todos los días, posibilitar permanentes reorganizaciones; es decir nuevos órdenes que se desordenan y reordenan sin cesar, revelando el misterio de las cosas y el sentido de residirla.

En este sentido residir la cocina campesina es comprender la cocina en acontecimientos dado que esta cocina es donde los alimentos son tomados de la huerta y puestos en la olla, donde las preparaciones toman tiempo y la calma de lo que se hace también conduce a la valoración de esos saberes trasmitidos en incomparables e irrepetibles platos y desde frágiles y rudimentarios objetos. Los objetos de la cocina solo son entonces amplios testigos, evidencia y cómplices de lo que en realidad es estar en una cocina. Y en el fogón de antaño, objetos gastados y primarios pero activos de instantes cautivos que desentrañan lo que pueden significar en la cocina y en el cocinar. Y siendo el fuego el organizador de la cocina tradicional, lo que está a su rededor es determinado por lo avivada que pueda estar la Ilama. Atizarla o apaciguarla expresan los ritmos de calma y aprecio en que se cocina. Y entre las chispas, las cenizas y el crujir, la candela abraza sartenes, ollas, pailas y calderos, no solo para transformar los alimentos sino para extenderse y oscurecer los peroles u ocultarse y arder entre las hornillas; pues el orden alrededor del fuego expresa cómo las manos disponen las múltiples formas cambiantes de los objetos. 
De la misma forma todo se acomoda justamente; tanto que en el momento de contemplarla a media luz asombra su ordenamiento, su disposición; todo está cerca de la mano, bateas para mezclar, platos para servir y hasta el indispensable molino que tiene un lugar definido. Ningún objeto molesta, ninguno se hace más importante que otro, todo se amolda al espacio. Abajo en el suelo, al lado de la leña, y arriba en las paredes. Que llenas de artefactos, parece intentar borrar lo teñido por la hoguera. Incluso el taburete se destaca entre la opacidad del lugar, ya que no tiene lugar definido se acomoda y reacomoda en la cocina según necesidad. Se acerca al fuego para ayudar a esperar las preparaciones, se aleja del calor para comer junto con otros, se coloca cerca de la entrada para refrescar o esperar la llegada de alguien, se acerca a lugares poco alcanzables, vuelve a la cocina el espacio relevante de la casa campesina, permite descansar de las jornadas de preparación y estar en soledad pero también disfrutar y compartir en las elaboraciones y de las comidas.

En definitiva, unos acontecimientos que inseparables del ser humano permanecen entre las modernas cocinas; aunque con esto se encaminara el mundo a dejar todo pasado atrás y comenzar un futuro prometedor con nuevos artefactos para un mejor vivir que permite cambiarlo todo hasta los valores que sellan la participación y la compañía en una cocina o el sosiego de lo que implica su quehacer. La cotidianidad moderna proclama que se puede dejar a un lado lo que se vive para construir otra forma nueva de vida, como si fuera tan fácil despojar al ser humano de esa carga enriquecedora del pasado que nunca deja de insistir. Pues las cocinas del movimiento moderno como la de Villa Savoye de Le Corbusier o la cocina en las casas adosadas de J.J.P Oud que más que modernas y ordenadas solo con su configuración insisten en recordar de la falta de aquellas cocinas olvidadas que calientan, reúnen y dejan contar los sucesos del día. Una infinita contienda entre costumbres y nuevos modos de vivir, simplemente necesaria para comprender que las viejas cocinas que 
parecen abandonadas se presentan una y otra vez en escondidos y anhelados momentos domésticos dentro de reinantes cocinas modernas (Figura 3).

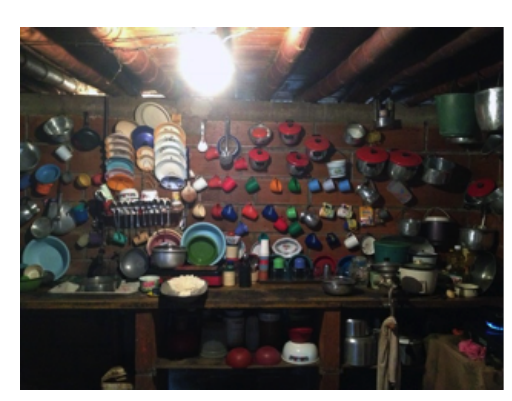

Figura 3. La resistencia del quehacer de cocinar.

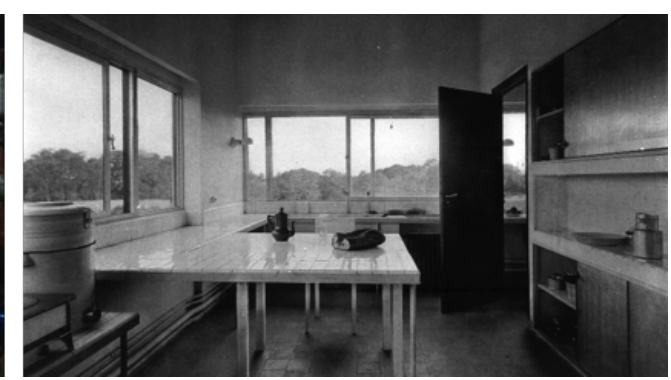

\section{Lo vivido en la cocina: un palpable encuentro con su quehacer}

Este fragmento expone lo que en reales cocinas de ciudad a menudo se presenta. Unas cocinas que pasan por alto el murmullo de su importancia y, además, un quehacer que plural también se torna singular. Una etapa en la investigación en la que se desempolvaron voces, pensamientos y cocinas que se despojaron de toda apariencia y se presentaron en la investigación como la forma de hacer y pensar del ser humano tan cautivadora, generosa y auténtica. Un espejo reflejo del ser humano donde se reclama de su laboriosidad, donde resuena que cocinar y comer es más que solo alimentar el cuerpo y donde el diseño intenta reconquistar en el significado de los objetos la vida cotidiana de los actuales tiempos.

${ }^{3}$ El contraste entre la cocina campesina a partir de la fotografía de Daniel Fernando Chica "El profesor Yarumo" vereda El Tigre Salamina Caldas 2016. Y la cocina moderna a partir de fotografía "Kitchen" del Libro Le Corbusier le Grand p. 210, 2008. 
Si bien la cotidianidad se vive sin causar mayor importancia es normal pasar por alto su distinción y su significación, ya que como lo explica Carolyn Korsmeyer (2002):

[...] no siempre está claro el modo en que la comida en compañía se transforma de energía en banquete, y de satisfacción de una necesidad en un lazo social. Cuando uno está acostumbrado a todo esto, y cuando este tipo de comida ha pasado a formar parte de la rutina diaria o anual, las pautas de significación que adquiere la comida pueden llegar a ser difíciles de distinguir. (p. 252)

Esto es cómo lo obvio, se ha vuelto costumbre, y para quien prepara a diario el desayuno lo que pasa frente a los ojos que es fácil de ver, lo ya reconocido, ya no genera asombro porque de alguna forma se asimila repetido y su significación ya no significa puesto que la costumbre nubla los destellos de sentido que tiene lo cotidiano. Sin embargo hay quienes mueven los rieles del obscuro telón porque saben ver el mundo ordinario, lo palpan, lo sienten y lo comprenden, entrando en su profundidad, en la detención de los instantes que le dan un giro a la cotidianidad, buscan extraer lo que callan las cocinas y lo vuelven elocuente al manifestarlo en el asombro de los acontecimientos que tiene su rutina.

Y es precisamente lo que hace con los objetos de la cocina la artista Martha Rosler (1975) en el performance: "Semiotics of the Kitchen"; mostrando un número de objetos como amplio es el alfabeto -y como extenso también es la cantidad de artefactos para la cocina-, utilizando uno para cada letra y terminado de la $\mathrm{U}$ a la $\mathrm{Z}$ con movimientos de los brazos sujetando un cuchillo y un tenedor —es que lo que no existe se soluciona de alguna forma con lo que a mano se tenga, así es la cocina- Y con sus gestos y movimientos exagerados vuelve una parodia, una sorpresa, el uso de los artefactos. Que no es para nada vacía; se palpa el sometimiento al que se encuentra la mujer en la cocina, a sus objetos, y a su quehacer. Un silencio que Rosler lo hace evidente con cada objeto que bruscamente utiliza. Estos objetos que suenan, que se 
tropiezan con otros, que hacen mover al cuerpo de forma particular, y que lo detiene en repeticiones toscas, son los que hablan del esfuerzo, el acierto, la torpeza y sobre todo de la disposición que se tiene para cocinar. Son los que canalizan la rabia, la molestia y la opresión que también tiene la cotidianidad.

En este sentido despertar de la rutina las dormidas, pero asombrosas maneras de hacer del ser humano es ver entre lo plural de su quehacer también lo singular y hallar - al igual que Rosler - los murmullos que esconde lo cotidiano; objetos salvados de su insignificancia al resarcir las importancias ocultas de un quehacer y con unos artefactos que ocasionan la cotidianidad de cocinar. Por ello la búsqueda entre modernas cocinas de ciudad se tornó amplia pero sustanciosa porque la inspección entre aquellos artefactos y alimentos, que se presentan una y otra vez independientes de lo que tiempos actuales puedan usurpar en su lugar, permitió la configuración de relatos que cuentan de aquello que invisible habla de la cocina. Del diseño en la reconquista de la vida cotidiana a través de los significados de sus artefactos y de los detalles de su apropiación y permanencia.

Es por lo anterior que se tomaron en cuenta artefactos como la radio porque todavía acompaña en la cocina, el lugar más informado de la casa que avisa de las posibles idas y vueltas del día. Como también de la olla exprés que muestra del murmullo del tiempo y que marca pitidos para la atención de la preparación, un saber de otros tiempos que recalca de mucha precaución. $\mathrm{O}$ la olleta y el bolinillo que Ilenan de paciencia el esperar su hervor y también su limpieza puesto que sus formas detienen a cualquier afanado a esperar, observar, saborear y lavar lo que se logró pegar. O la nevera y alacenas que hablan de épocas de la abundancia, de la quincena e incluso de la indecisión o de las galguerías que aquellas recolectan, o de las pailas que hacen alusión a los infaltables huevos y a su preferida preparación, o de las cafeteras que cuentan de aquellos expertos en café de olleta, o los pequeños electrodomésticos, 
las vajillas y los utensilios que logran atiborrar a la cocina y de las ollas que cuentan del menú, de las preferidas y de lo que experimentado han enseñado para encontrar la sazón de la familia.
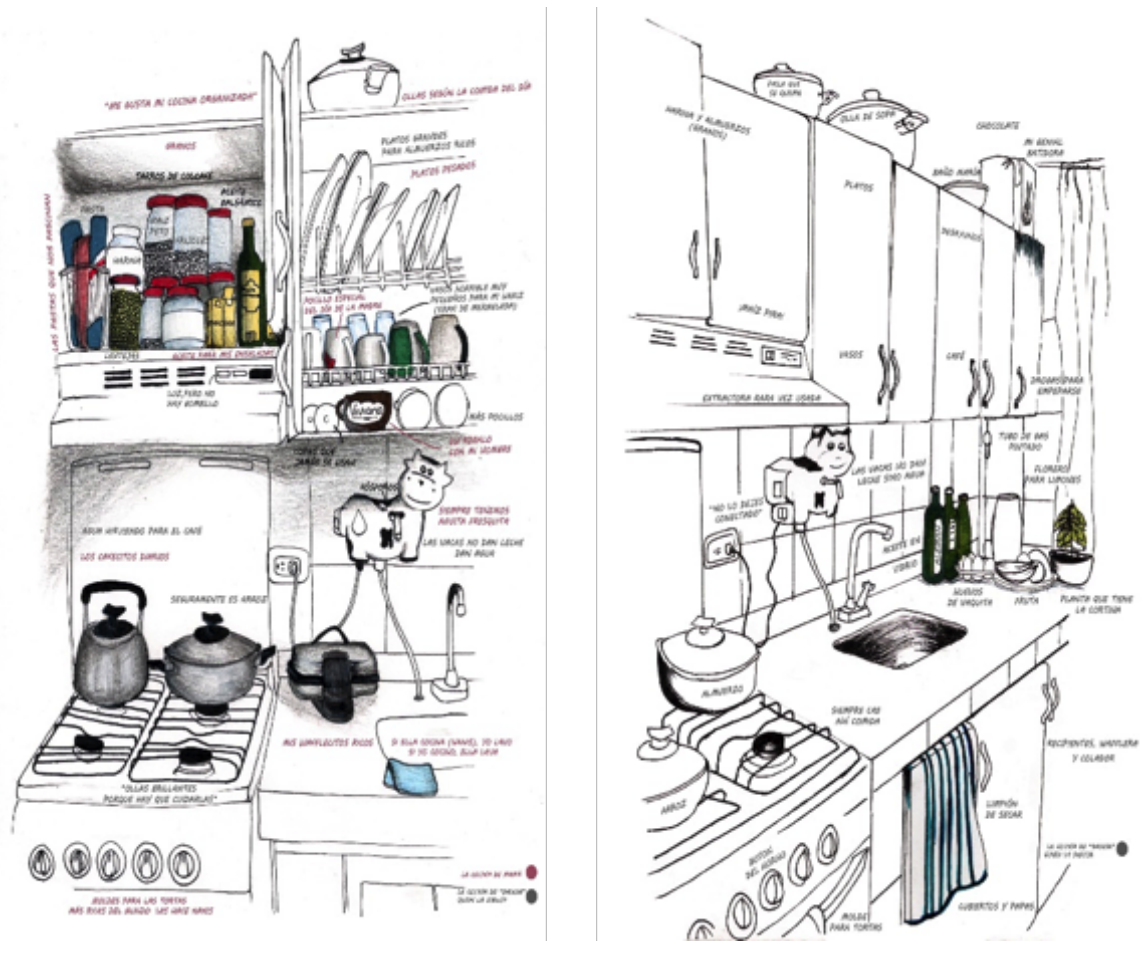

Figura 4. Singulares instantes domésticos. Fuente: cocina esbozada a partir de mapas mentales de estudiantes de la Universidad de La Salle. 
En definitiva, un palpable encuentro con el quehacer está en sacar a flote lo invisible de cocinar; un atrevimiento del diseñador al revelar acontecimientos con la intención de combatir el olvido de su quehacer, de su vivencia o simplemente lo que cocinar hace para el ser humano. Un quehacer que deja ver cómo se es y cómo el cuerpo preparado para aquella ardua tarea, también construye las nobles voces de lo cotidiano; esos silencios del cuerpo tan particulares y a la vez tan plurales que pasan sin siquiera ser notados pero que muestran e insisten que la cocina olvidada —la que está en el cocinar- es la que se hace necesaria para recuperar la habilidad y la presencia, la permanencia y el gozo, la preparación y los alimentos, la sabiduría y su práctica, la palabra y la compañía, los artefactos y la vivencia en el pequeño mundo doméstico de la ciudad; ese que sumado logra diferenciarse entre las múltiples culturas (Figura 4).

\section{Conclusiones}

Es indiscutible que este estudio de la cocina abrió una manera distinta de comprenderla dado que hallar la cocina perdida en el acontecimiento generó interesantes singularidades para saber de la cultura, de los artefactos perdurables —porque aún son algunos perdurables-, de alimentos y preparaciones que guardan sus secretos en los artefactos que se elaboran y del diseño como provocador de una cocina hacia su esencia. Sobre todo al recordar que la cocina es un asunto de calma y aprecio, de asombros y de ensueño, pero también de realidades que entre la rutina son cambiantes; pues nada más monótono que cocinar y a la vez nada más original que eso que se quiere preparar. Por tanto, reivindicar la cocina en el cocinar es encontrar lo que perdido de la cocina se encuentra; ya que vivenciarla permite inquietarnos de las singularidades de su misterio y del diseño sin más permeado de sentido, vivencia, realidad y humanidad. 


\section{Referencias}

Aicher, O. (2001). Analógico y digital. Barcelona, España: Gustavo Gili.

Aicher, O. (2004). La cocina para cocinar: el final de una doctrina arquitectónica. Barcelona, España: Gustavo Gili.

Bachelard, G. (1986). La intuición del instante. Ciudad de México, México: Fondo de Cultura Económica.

Bodei, R. (2013). La vida de las cosas. Buenos Aires, Argentina: Amorrortu editores.

Buchanan, R. (2001). Design research and new learning. Design Issues, 17 (4), 3-23.

Corrodi, M. (2006). On the Kitchen and Vulgar Odors. En K. Spechtenhauser (Ed.), The Kitchen (pp. 21-42). Geneva, Switzerland: Birkhäuser-Publishers for architecture.

Espegel, C. (2007). Heroínas del espacio: mujeres arquitectos en el movimiento moderno. Buenso Aires, Argentina: Nobuko.

Espinet, M. (1984). El espacio culinario: de la taberna romana a la cocina profesional y doméstica del siglo XX. Barcelona, España: Tusquets Editores.

Esquivel, L. (2015). Intimas suculencias: tratado filosófico de cocina. Ciudad de México, México: Penguin Random House.

Giard, L. (1999). Hacer de comer. En M. De Certeau, L. Giard y P. Mayol, La invención de lo cotidiano: habitar, cocinar (pp. 151-231). Ciudad de México, México: Universidad Iberoamericana.

Giedion, S. (1978). Las mecanización toma el mando. Barcelona, España: Gustavo Gili. 
Grisales, A.L. (2015). Artesanía, arte y diseño: una indagación filosófica acerca de la vida cotidiana y el saber práctico. Manizales, Colombia: Universidad de Caldas.

Heidegger, M. (1953). La cosa. Ideas y Valores, 2 (7-8), 661-667.

Heidegger, M. (1964). La pregunta por la cosa. Buenos Aires, Argentina: Sur.

Korsmeyer, C. (2002). Comida, estética y filosofía. Barcelona, España: Paídos Ibérica.

Krippendorff, K. (2006). An exploration of Artificiality. Artifact, 1 (1), 17-22.

Lefebvre, H. and Levich, C. (1987). The everyday and everydayness. Yale French Studies, 73, 7-11.

Lévi-Strauss, C. (1970). Mitológicas I: lo crudo y lo cocido. Ciudad de México, México: Siglo XXI Editores.

Lupton, E. y Miller, J. (1995). El cuarto de baño, la cocina y la estética de los desperdicios. Procesos de eliminación. Madrid, España: Ayuntamiento de Madrid.

Mejía Vallejo, M. (2011). Colombia campesina. Bogotá, Colombia: Villegas Editores S.A.

Norman, D. (2010). El diseño de los objetos del futuro: interacción entre el hombre y la máquina. Madrid, España: Paidós.

Rigotti, F. (2001). Filosofía en la cocina: pequeña crítica de la razón culinaria. Barcelona, España: Herder.

Rosler, M. (1975). Semiotics of the Kitchen. Recuperado de https://www.moma. org/collection/works/88937.

Wilson, B. (2013). La importancia del tenedor: historias, inventos y artilugios en la cocina. Madrid, España: Turner Noema. 
Zabalbeascoa, A. (2004). Prólogo. En O. Aicher, La cocina para cocinar: el final de una doctrina arquitectónica (pp. 7-11). Barcelona, España: Gustavo Gili.

Como citar: Bustacara, S.M. (2019). En busca de la cocina perdida. Los singulares instantes del quehacer de cocinar. Revista KEPES, 16 (19), 123-149. DOI: 10.17151/kepes.2019.16.19.6 